Supplement of Atmos. Meas. Tech., 12, 1659-1671, 2019

https://doi.org/10.5194/amt-12-1659-2019-supplement

(C) Author(s) 2019. This work is distributed under

the Creative Commons Attribution 4.0 License.

(c) (1)

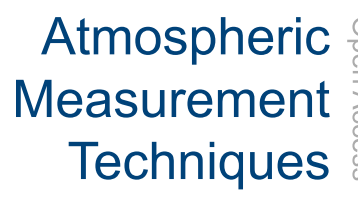

Supplement of

\title{
Ultrasonic nebulization for the elemental analysis of microgram-level samples with offline aerosol mass spectrometry
}

Rachel E. O'Brien et al.

Correspondence to: Rachel E. O’Brien (reobrien@wm.edu)

The copyright of individual parts of the supplement might differ from the CC BY 4.0 License. 

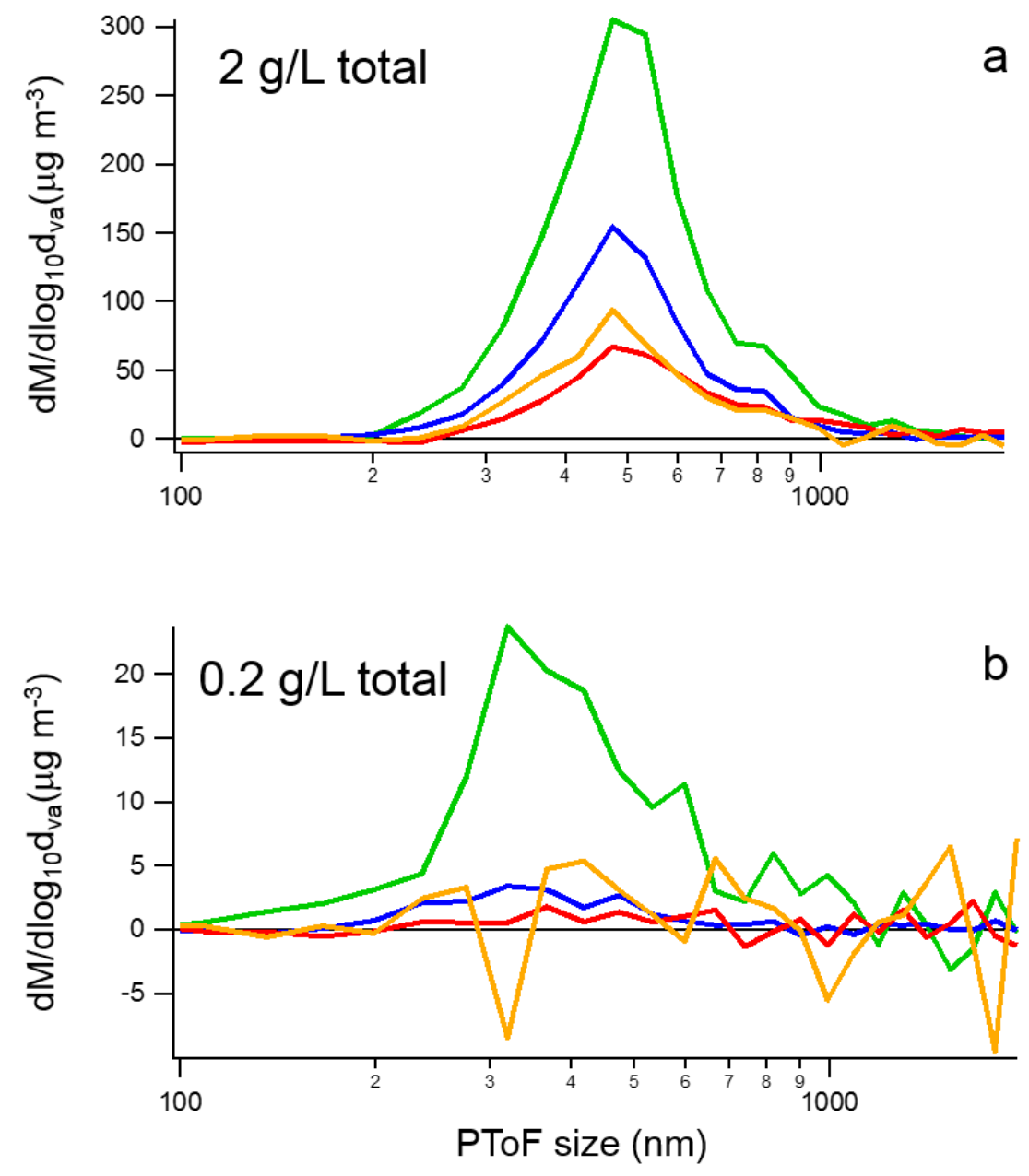

Figure S1. AMS pToF mass distributions from continuous injection of aqueous solutions of $\mathrm{NH}_{4} \mathrm{NO}_{3},\left(\mathrm{NH}_{4}\right)_{2} \mathrm{SO}_{4}$, and mannitol. Measurable shifts in the distribution can be achieved for more concentrated solutions ((a) $2 \mathrm{~g} / \mathrm{L}$; size distribution centered at $500 \mathrm{~nm}$ ) or more dilute solutions ((b) $0.2 \mathrm{~g} / \mathrm{L}$; size distribution centered at $300 \mathrm{~nm}$ ). Thus, these data demonstrates that fine particles formed from nebulizing solutions with concentrations greater than $\sim 0.2 \mathrm{~g} / \mathrm{L}$ have an appropriate size distribution for direct measurement by the AMS. For these samples, the size distribution of the components is fairly uniform consistent with the formation of homogenous particles in the nebulizer. 


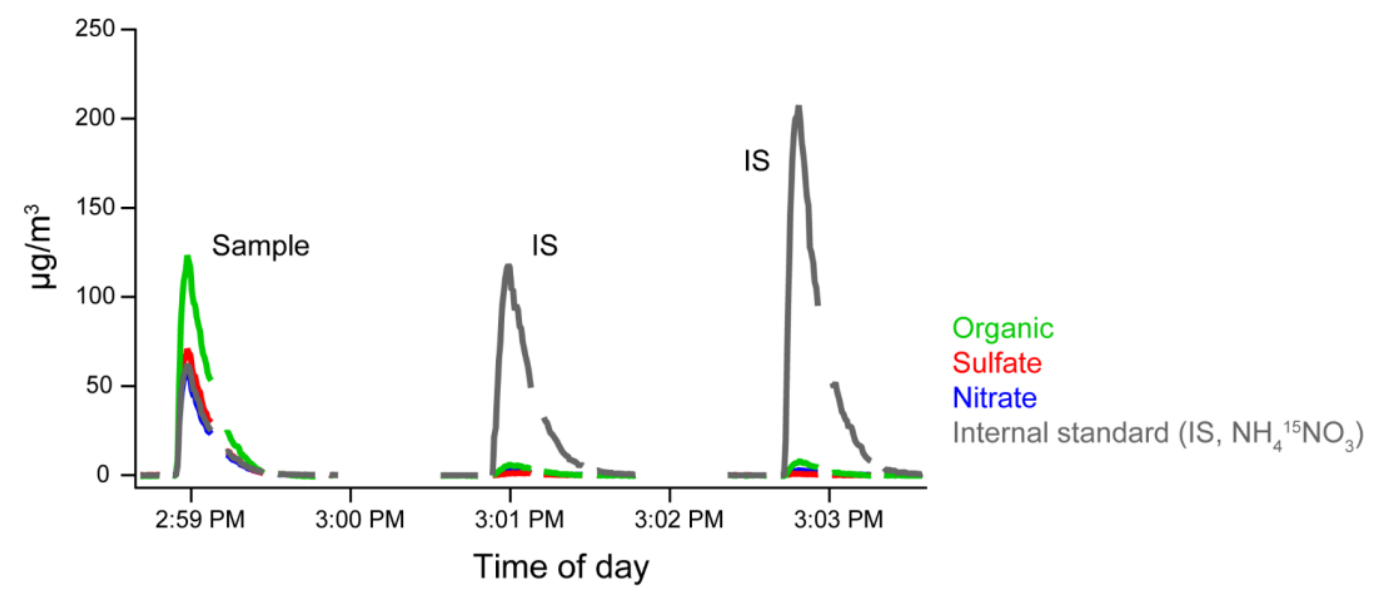

Figure S2. Discrete aerosol pulses for a solution with $0.125 \mathrm{~g} / \mathrm{L}$ of each component (first pulse) followed by two nebulizations of $1 \mathrm{~g} / \mathrm{L}$ solution of the internal standard (grey, $\mathrm{NH}_{4}{ }^{15} \mathrm{NO}_{3}$ ) with no rinse on the Kapton surface.

\section{Memory Effects}

For typical solutions containing small polar organic molecules and salts, the sample mass that remains on the film surface after the nebulization is small. Figure S2 shows a time trace for a discrete injection of $4 \mu \mathrm{L}$ of a solution of $\left(\mathrm{NH}_{4}\right)_{2} \mathrm{SO}_{4}, \mathrm{NH}_{4} \mathrm{NO}_{3}, \mathrm{NH}_{4}{ }^{15} \mathrm{NO}_{3}$, and mannitol each at $0.125 \mathrm{~g} / \mathrm{L}$ (first pulse). The two subsequent pulses are generated from $4 \mu \mathrm{L}$ drops of a $1 \mathrm{~g} / \mathrm{L}$ solution of $\mathrm{NH}_{4}{ }^{15} \mathrm{NO}_{3}$ placed directly on the same spot as the sample. The mass of $\mathrm{SO}_{4}, \mathrm{NO}_{3}$, and mannitol that remained on the Kapton film and observed in the next pulses is $1-2 \%$ of the original mass observed. These values are within $10 \%$ of the signal for a blank run on a freshly cleaned Kapton film. Thus, minimal cleaning of the Kapton surface was needed between runs for samples with composition similar to the one described above. To account for potential contamination, runs of the internal standard solution were included between samples. 
No carryover from one run to the next has been observed due to droplets from previous discrete injections falling back down to the surface of the film after the sample has been loaded and the SVN sealed in preparation for nebulization. This is likely due to the fact that the surface area of the droplet is very small on the Kapton film and lies in the center of the film with only the open glass tube above it. Also, the time between injections is long enough for a large fraction of the droplet mass on the sides of the SVN to evaporate. However, some ejected droplets are observed to fall from the SVN sides and pool up on the film with continuous injection at $20 \mu \mathrm{L} / \mathrm{min}$ with an aqueous solution. This behavior has not been observed for continuous injections of solutions with more volatile solvents such as methanol.

\section{Nebulization Efficiency and Calibration Curves}

The same solutions were run to generate the calibration curves and the nebulization efficiency plot. For the nebulization efficiency, exactly $4 \mu \mathrm{L}$ of the solution was placed on the Kapton film for each injection. This provides the known mass of material placed on the film. The stock solution for each analyte was $10 \mathrm{~g} / \mathrm{L}$, the table below shows the volumes of each stock added to generate the solutions. 
Table S1. Volumes of stock solutions used in the standard solutions

\begin{tabular}{cccccc}
\hline Standard name & $\mathrm{NH}_{4}{ }^{15} \mathrm{NO}_{3}$ & $\left(\mathrm{NH}_{4}\right)_{2} \mathrm{SO}_{4}$ & $\mathrm{NH}_{4} \mathrm{NO}_{3}$ & Organic & $\mathrm{H}_{2} \mathrm{O}$ dilution \\
& $(\mu \mathrm{L})$ & $(\mu \mathrm{L})$ & $(\mu \mathrm{L})$ & $(\mu \mathrm{L})$ & $(\mathrm{mL})$ \\
\hline $\mathrm{A} 1$ & 100 & 20 & 20 & 20 & 1.6 \\
$\mathrm{~A} 2$ & 100 & 50 & 50 & 50 & 2.5 \\
$\mathrm{~A} 3$ & 100 & 70 & 70 & 70 & 3.1 \\
$\mathrm{~A} 4$ & 100 & 100 & 100 & 100 & 4 \\
\hline
\end{tabular}

The efficiency plot in Figure 3 shows the results of six replicate injections of the above solutions. Figure S3 shows the same plot with the solutions that contributed to each set of replicates labeled either above or below the data sets. The trends shown here, where the greatest net mass was observed for the first calibration solution, are not necessarily characteristic. What is consistently observed is efficiencies on the order of $0.02-0.06 \%$ and ratios of analytes to the internal standards that are replicable and correlate to the ratios of the components in the solutions. This last feature enables the use of the internal standard in the calibrations. 


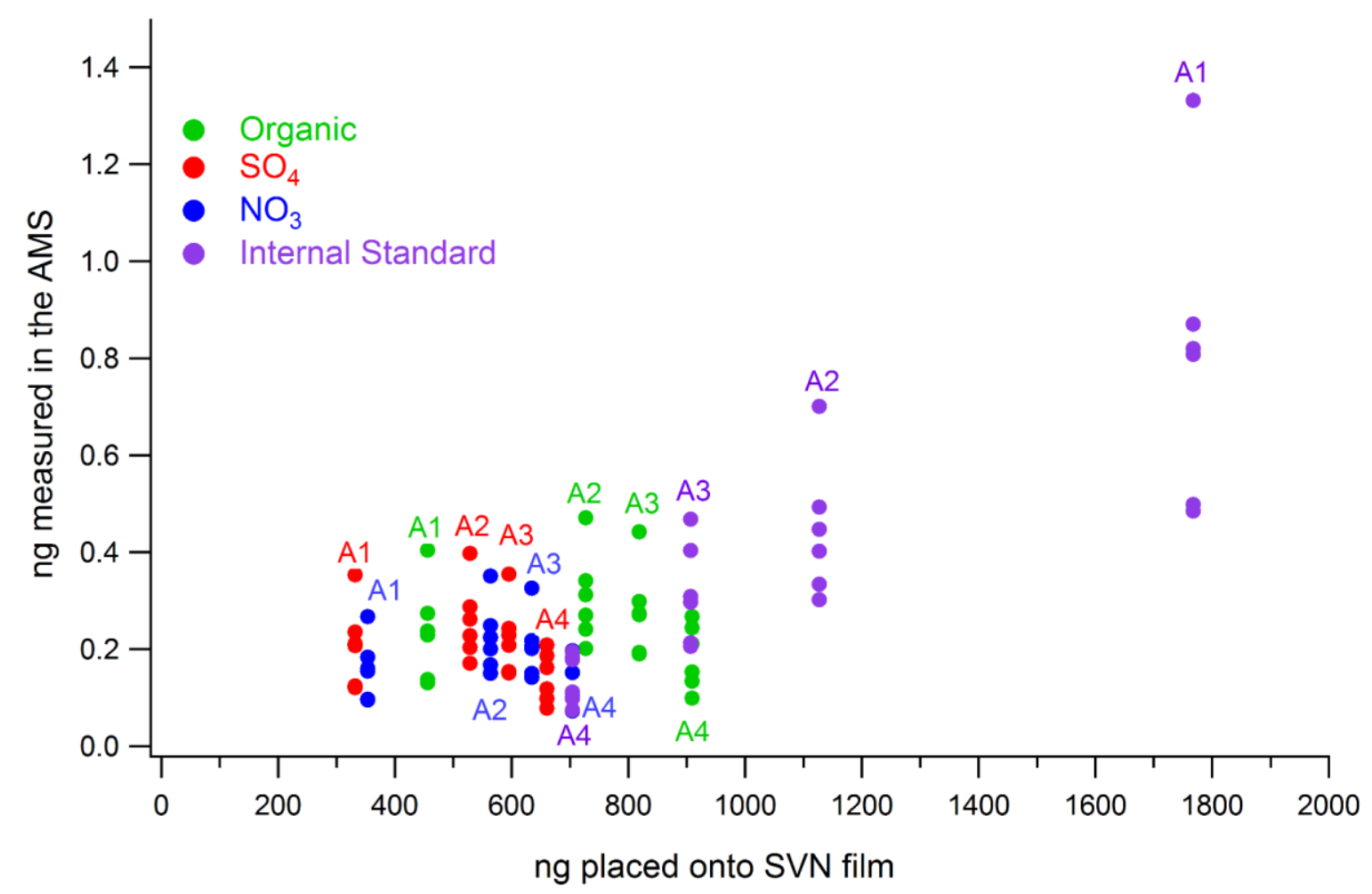

Figure S3. Replicate of Figure 3 in the text with the contributing solutions labeled above each sample set. 